\title{
Prevalence of metabolic syndrome (MetS) among male Kuwaiti adolescents aged 10 - 19 years
}

\author{
Abdulwahab Al-Isa \\ Department of Community Medicine, Faculty of Medicine, Kuwait University, Kuwait; alisa@hsc.edu.kw \\ Received 14 November 2012; revised 12 February 2013; accepted 10 May 2013 \\ Copyright (C) 2013 Abdulwahab Al-Isa. This is an open access article distributed under the Creative Commons Attribution License, \\ which permits unrestricted use, distribution, and reproduction in any medium, provided the original work is properly cited.
}

\begin{abstract}
Background: The prevalence of overweight and obesity are high in Kuwait. Metabolic Syndrome is associated with both. It is expected to find the syndrome higher than that in other countries. Objective: To assess the prevalence of MS using two different diagnostic criteria, the International Diabetes Federation (IDF) and the National Cholesterol Education Program-Third Adult Treatment Panel Modified for age (NCEP-ATP III). Study design: A multi-stage random sample study. Methods: The analysis of data for this study was based on a sample of $\mathbf{3 0 3}$ male Kuwaiti adolescents, 10 - 19 years of age selected from intermediate and high schools. Anthropometric measurements and biochemical tests on blood samples were carried out. The IDF criterion requires waist circumference (WC) plus two of the following criteria: triglycerides (TG), high density lipoprotein (HDL), fasting blood sugar (FBS) and blood pressure (PB). The ATP III criterion requires three of the above parameters. The parameters mentioned must show increase in their values except for HDL which must show decrease in either criterion used. Results: Each of the two criteria revealed that the prevalence of MS was $14.8 \%$ and $19.5 \%$, using the IDF and the ATP III criteria, respectively. HDL decreased in each of the two diagnostic criteria and the other four parameters increased, satisfying the diagnostic requirements of either criterion. Conclusions: Significant implications may be drawn from these results, especially when it comes to being at risk of type 2 diabetes (T2D) and cardiovascular disease (CVD).
\end{abstract}

\footnotetext{
*Declaration of conflicting interests: None declared.
}

Keywords: Metabolic Syndrome; Male; Kuwaiti; Prevalence

\section{INTRODUCTION}

Since overweight $\left(\mathrm{BMI} \geq 25 \mathrm{Kg} / \mathrm{m}^{2}\right)$ and obesity (BMI $\geq 30 \mathrm{Kg} / \mathrm{m}^{2}$ ) are high in Kuwait $[1,2]$ and since both are associated with metabolic syndrome (MS), it may be concluded that the prevalence of MS is also high [3]. In recent years, the prevalence of obesity in developing countries has tripled $[3,4]$. MS has been modified for age. BP (blood pressure), triglycerides and high density lipoproteins (HDL) are more frequently altered variables among children and adolescents [5]. However, defining MS among children and adolescents is not straight-forward but it has been suggested that it may be associated with insulin resistance [6]. The development of MS has been suggested to be influenced by the environment, unhealthy lifestyle and diet [7]. Moreover, MS has been reported to be genetically predisposed [8]. The association of visceral obesity and insulin resistance has been suggested. Insulin resistance predisposes individuals with such morbid conditions as cardiovascular disease, diabetes and alcoholic fatty liver disease $[9,10]$.

The high prevalence of overweight and obesity in the Gulf Arab region makes MS a major public health problem that has to be dealt with. Two criteria were used for the definition of MS in this study, the International Diabetes Federation (IDF) and the National Cholesterol Education Program (NCEP) Adult Treatment Panel III modified for age (ATP III). The IDF definition considers central obesity as a prerequisite for MS plus two other parameters, whereas the ATP III definition considers MS when it satisfies at least three of the tested five parameters plus two other parameters, all shown in Table 1 [11-17]. The objective of this study was to assess the prevalence of MS among Kuwaiti adolescent males, using the IDF and ATP III criteria. 
Table 1. Cut-off points of IDF and ATP III criteria.

\begin{tabular}{|c|c|c|c|c|c|}
\hline \multirow{2}{*}{\multicolumn{2}{|c|}{ Parameters }} & \multicolumn{2}{|c|}{ IDF Cut-off points } & \multicolumn{2}{|c|}{ ATP III Cut-off points } \\
\hline & & $10-<16 \mathrm{Y}$ & $16+\mathrm{Y}$ & Adolescents & Adults \\
\hline \multirow[t]{2}{*}{$\mathrm{WC}(\mathrm{cm})$} & Male & $\begin{array}{c}\geq 90^{\text {th }} \\
\text { percentile }\end{array}$ & $\geq 94$ & $\begin{array}{c}\geq 90^{\text {th }} \\
\text { percentile }\end{array}$ & $>102$ \\
\hline & Female & $\begin{array}{l}\text { or adult } \\
\text { cut-off, } \\
\text { if lower }\end{array}$ & $\geq 80$ & $\begin{array}{c}\geq 90^{\text {th }} \\
\text { percentile }\end{array}$ & $>88$ \\
\hline \multicolumn{2}{|c|}{$\mathrm{TG}(\mathrm{mmol} / \mathrm{L})$} & $\geq 1.7$ & $\geq 1.7$ & $\geq 1.24$ & $\geq 1.7$ \\
\hline \multicolumn{2}{|c|}{ HDL (mmol/L) Male } & $<1.03$ & $<1.03$ & $\leq 1.03$ & $<1.03$ \\
\hline \multicolumn{2}{|c|}{ Female } & $<1.29$ & & $<1.29$ & \\
\hline \multicolumn{2}{|c|}{$\mathrm{BP}(\mathrm{mmHg})$} & $\geq 130 / 85$ & $\geq 130 / 85$ & $\begin{array}{c}\geq 90^{\text {th }} \\
\text { percentile }\end{array}$ & $\geq 130 / 85$ \\
\hline \multicolumn{2}{|c|}{ Glucose $(\mathrm{mmol} / \mathrm{L})$} & $\geq 5.6$ & $\geq 5.6$ & $\geq 6.1$ & $\geq 6.1$ \\
\hline
\end{tabular}

$\mathrm{WC}=$ Waist Circumference, $\mathrm{TG}=$ Triglyceride, $\mathrm{HDL}=$ High Density Lipoprotein, $\mathrm{BP}=$ Blood Pressure; " $\mathrm{IDF}$ criterion for metabolic syndrome identified as the presence of high WC plus two or more of the listed factors; *ATP criterion for metabolic syndrome identified as the presence of three or more of the listed factors.

\section{METHODS}

\subsection{Sampling}

This has been described in detail earlier but it is presented here with some modification [18]. A multi-stage sampling procedure was followed. There are six governorates in Kuwait, each with a set of school levels from kindergarten to secondary. A list of the schools was obtained from the Ministry of Education. Two of the six governorates were randomly selected for the study, the Capital and Hawally governorates. From each of the two governorates, one intermediate and one secondary school were randomly selected. Owing to the invasive nature of the study, the ethical approval was taken from the local Ethics Committee of the Faculty of Medicine. Every student was invited to participate, suspecting perhaps a low participation rate due to the invasive nature of the study. A consent form was given to each student to be signed by his her guardian before the measurements and tests started.

The subjects chosen for the study were all healthy students. Each student was asked if he suffers from a chronic disease. This was confirmed or not by the guardian, the school, and the pediatrician who kept special files for unhealthy cases. Excluded were those who were confirmed as suffering from chronic diseases.

\subsection{Questionnaire and Measurements}

Sociodemographic and health-related information were obtained through a questionnaire. The students were helped in this effort when needed. In addition, a blood sample was collected through a venipuncture from each participant after fasting for 10 hours. The specimens were kept cool in an ice box until separation of blood from plasma or serum; the latter were frozen at $-80^{\circ} \mathrm{C}$ prior for biochemical analysis. Anthropometric measurements were carried out which, for this study, included waist circumference (WC). WC was measured using a measuring tape placed midway between the inferior margin of the ribs and the superior border of the iliac crest. The WC measurement was done by the same investigator so as to avoid inter-observer variations.

\subsection{The Criteria for Diagnosing Metabolic Syndrome (MS)}

Two criteria were arbitrarily chosen from the available criteria in the literature. These were the International Diabetes Federation (IDF) and the National Cholesterol Education Program, Third Adult Treatment Panel modified for age (ATP III), as there were no criteria recommended for Arab population. According to the IDF criterion, MS is diagnosed by high WC plus two other variables with cut-off values modified for age. According to the modified ATP III criterion, the diagnosis of MS must be indicated by the presence of three of the listed criteria. The cut-off points used are shown in Table 1. After reviewing the literature, no studies diagnosing MS in Arab adolescents were found. The purpose of this study was to estimate the prevalence of MS among male Kuwaiti adolescents aged 10 - 19 years of age, using two diagnostic criteria: the IDF and the ATP III, modified for age.

\section{STATISTICAL ANALYSIS}

Version 17 of the Statistical Package for Social Sciences software (SPSS, Inc., Chicago, USA) was used for data entry and analysis. Descriptive statistics were used which included mean, standard deviation and proportions. Moreover, sensitivity and specificity measures of the two MS criteria were used.

\section{RESULTS}

The mean age of the sample was $14.16 \pm 2.17$ years. Table 2 shows the mean and \pm standard deviation $( \pm$ SD) and MS diagnostic values for both the IDF and the modified ATP III criteria. The anthropometric and biochemical variables presented in the table include $\mathrm{WC}, \mathrm{TG}$, HDL, glucose, systolic and diastolic BP. It was found that the prevalence of MS, using the IDF was higher than the modified ATP III criterion for the diagnosis of MS. Table 3 shows the sensitivity and specificity of both the IDF and modified ATP III diagnostic criteria of MS.

\section{DISCUSSION}

The prevalence of obesity among Kuwaiti adolescents was reported to be high. The association of obesity with MS has been well established. This study found that the 
Table 2. Parameters and MS prevalence among Kuwaiti male students, according to IDF and ATP III criteria.

\begin{tabular}{ccccc}
\hline $\begin{array}{c}\text { Anthropometric \& } \\
\text { biochemical } \\
\text { parameters }\end{array}$ & Mean & \pm SD/range & \multicolumn{2}{c}{ MS diagnostic criteria } \\
\cline { 4 - 5 } & & & IDF & $\begin{array}{c}\text { Modified } \\
\text { ATP III }\end{array}$ \\
\hline $\begin{array}{c}\text { Waist } \\
\text { circumference (cm) }\end{array}$ & 78.4 & 15.3 & $17.7 \%$ & $11.1 \%$ \\
Triglyceride (mmol/L) & 0.97 & 0.62 & $8.2 \%$ & $22.9 \%$ \\
HDL (mmol/L) & 1.07 & 0.29 & $44.6 \%$ & $46.3 \%$ \\
Glucose (mmol/L) & 5.2 & 0.77 & $16.5 \%$ & $3.3 \%$ \\
BP (systolic) & 122.93 & 12.0 & & \\
BP (diastolic) & 80.81 & 8.53 & $60.8 \%$ & $13.9 \%$ \\
MS prevalence & & & $11.7 \%$ & $9.8 \%$ \\
\hline
\end{tabular}

MS = Metabolic Syndrome.

Table 3. Sensitivity and specificity of the IDF and the modified ATP III criteria.

\begin{tabular}{cccc}
\hline \multicolumn{4}{c}{ MS diagnostic criteria } \\
\hline & ATP III (+MS) & ATP III (-MS) & Total \\
\hline IDF (+MS) & 34 & 10 & 44 \\
IDF (-MS) & 25 & 228 & 253 \\
Total & 59 & 238 & 297 \\
\hline
\end{tabular}

MS $=$ Metabolic Syndrome Sensitivity of $\mathrm{IDF}=58 \%$; PPV $=0.773$ Specificity of IDF $=95.7 \%$; NPV $=0.099$.

prevalence of MS among male Kuwaiti adolescents aged 10 - 19 years, being the first of its kind, to be 11.7 and $9.8 \%$, using the IDF and the ATP III criteria, respectively. A comparison between MS prevalence among male $\mathrm{Ku}-$ waiti adolescents and other countries, using the two criteria are shown in Figures $\mathbf{1}$ and 2. Obesity increases the risk of MS by three folds [19]. It is expected that both developed and developing countries will suffer from the MS pandemic $[19,20]$. In Chinese boys, MS was present $0.2 \%$ in normal weight, $6.0 \%$ in overweight, and $28.1 \%$ in obese adolescents. Obesity and BP were associated with MS [21]. MS was 16 times higher among overweight than normal weight [22]. Among Americans, MS increased to $78.7 \%$ among the overweight, $6.8 \%$ among the at-risk adolescents $\left(85^{\text {th }}-95^{\text {th }}\right.$ percentile). Low HDL, a parameter of MS in both criteria used in this study, showed the highest increase among Korean males and dyslipidemia was the principal contributor to MS [23].

The literature is devoid of any criterion specific for adolescent Arab populations. Two studies, one conducted in Kuwait, among young adults [24] and the other among adults in Iraq [25], used the available criteria in the literature. Therefore, cut-off points are much needed for adolescents of Arab populations.

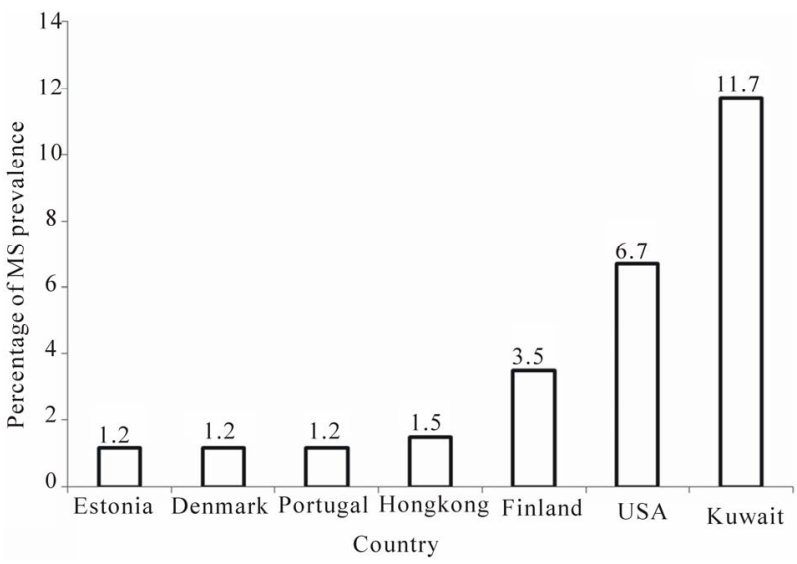

Figure 1. Metabolic Syndrome (MS) prevalence among Kuwaiti male adolescents, according to the IDF criterion, as compared to other countries.

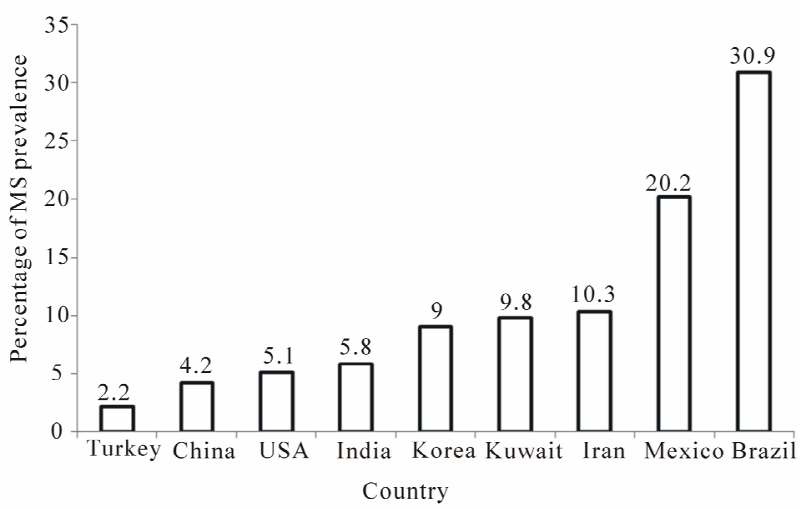

Figure 2. Metabolic Syndrome (MS) prevalence among Kuwaiti male adolescents, according to the ATPIII criterion, as compared to other countries.

Obesity often persists into adulthood, which presents a future risk of type 2 diabetes (T2D) and cardiovascular disease (CVD). Obesity is associated with MS and, therefore, early interventions may reduce the risk of such morbid conditions as CVD and T2D [20]. The high prevalence of MS among male Kuwaiti adolescents requires intervention programs aimed at reducing obesity and decreasing the risk of morbid conditions associated with it.

The findings of this study cannot be generalized to the rest of the male Kuwaiti adolescents because the sample was randomly selected from one intermediate and one secondary school in each of two, out of six, randomly selected governorates, which happened to be populated mostly by urban inhabitants, i.e., the findings in the selected four schools cannot be reasonably generalized to the rest of the population. On the other hand, this bias may be weak because Kuwait is a small country and mostly urban, but it is worth stating this here.

Another possible bias in the results may be related to the low rate, because of the invasive nature of the study, 
of parental and/ or students' consent to take part in the study despite the fact that consent forms are given to all students. It is possible that those who gave consent have more health awareness and knowledge about the value of the procedure, if not for now but may be for the future. It will allow them to take the necessary precautions to avoid being at risk of some morbid conditions associated with MS. On the other hand, the high refusal rate may vary with different strata of the population and whether or not the rich or the more educated had higher participation rate or a combination of the whole strata, including the poor or less educated, makes it difficult to be certain that such bias would have affected our results. Furthermore, it is not certain that male Kuwaiti students could always have followed the requirements of coming to school fasting for the previous ten hours and, therefore, carrying out blood tests may not come with ease.

\section{ACKNOWLEDGEMENTS}

The authors are grateful to Kuwait University Research Administration and Kuwait Foundation for the Advancement of Sciences for funding this study (MC 01/04). We are also grateful to the Ministry of Education, to all participating adolescents and their parents; and for the directors of selected schools for facilitating data collection.

\section{REFERENCES}

[1] Al-Isa, A.N. (2003) Are Kuwaitis getting fatter? Nutrition and Health, 17, 185-197. doi: $10.1177 / 026010600301700301$

[2] Al-Isa, A.N. (2004) Body mass index, overweight and obesity among Kuwaiti intermediate school adolescents aged 10-14 years. European Journal of Clinical Nutrition, 58, 1273-1277. doi:10.1038/sj.ejen.1601961

[3] Kelishadi, R. (2007) Childhood overweight, obesity and the metabolic syndrome in developing countries. Epidemiologic Reviews, 29, 62-76. doi:10.1093/epirev/mxm003

[4] Hossain, P., Kawar, B. and El Nahas, M. (2007) Obesity and diabetes in the developing world-A growing challenge. The New England Journal of Medicine, 356, 213-215. doi:10.1056/NEJMp068177

[5] Cook, S., Weizman, M., Auinger, P., Nguyen, M. and Dietz, W.H. (2004) Prevalence and trends of a metabolic syndrome phenotype among US adolescents 1999-2000 (metabolic syndrome/insulin resistance syndrome/pre-diabetes). Diabetes Care, 27, 2438-2443.

doi:10.2337/diacare.27.10.2438

[6] Hirschler, V., Caleagno, M.L., Aranda, C., Maccallini, G. and Jadzinsky, M. (2007) Can the metabolic syndrome identify children with insulin resistance? Pediatric Diabetes, 8, 272-277. doi:10.1111/j.1399-5448.2007.00282.x

[7] Alberti, K.G., Zimmet, P. and Shaw, J. (2006) Metabolic syndrome-A new world-wide definition. A consensus statement from the international diabetes federation. Diabetic Medicine, 23, 469-480. doi:10.1111/j.1464-5491.2006.01858.x

[8] Nikzamir, A., Nakhjavai, M., Golmohamadi, T. and Dibai, L. (2008) Association of angio-converting enzyme gene insertion/deletion polymorphism with metabolic syndrome in Iranians with type 2 diabetes mellitus. Archives of Iranian Medicine, 11, 3-9.

[9] Haffner, S.M. (2007) Abdominal adiposity and cardio metabolic risk: Do we have all the answers? The American Journal of Medicine, 120, S10-S16. doi:10.1016/j.amjmed.2007.06.006

[10] National Cholesterol Education Program (2001) Detection, evaluation and treatment of high blood cholesterol in adults (adult treatment panel). National Institute of Health, NIH Publication.

[11] Can, A.S. and Bersot, T.P. (2007) Analysis of agreement among definitions of metabolic syndrome in nondiabetic Turkish adults: A methodological study. BMC Public Health, 7, 353-362. doi:10.1186/1471-2458-7-353

[12] Gami, A.S., Witt, B.J., Howard, D.E., Erwin, P.J., Garni, L.A., Somers, V.K. and Montori, V.M. (2007) Metabolic syndrome and risk of incident cardiovascular events and death: A systematic review and meta analysis of longitudinal studies. Journal of the American College of Cardiology, 49, 403-414. doi:10.1016/j.jacc.2006.09.032

[13] Dekker, J.M., Girmain, C., Rhodes, T., Nijpels, G., Stehouver, C.D., Bouter, L.M. and Heine, R.J. (2005) Metabolic syndrome and 10-year cardiovascular disease risk in the Hoorn Study. Circulation, 112, 666-673. doi:10.1161/CIRCULATIONAHA.104.516948

[14] Lorenzo, C., Williams, K., Hunt, K.J. and Haffner, S.M. (2007) The national cholesterol education programAdult treatment panel III, international diabetes federation, and world health organization definitions of the metabolic syndrome as predictors of incident cardiovascular disease and diabetes. Diabetes Care, 30, 8-13. doi:10.2337/dc06-1414

[15] Malik, S., Wong, N.D., Franklin, S.S., Kamath, T.V., L'Italien, G.J., Pio, J.R. and Williams, G.R. (2004) Impact of the metabolic syndrome mortality from coronary heart disease, cardiovascular disease and all causes in United States adults. Circulation, 110, 1245-1250. doi:10.1161/01.CIR.0000140677.20606.0E

[16] Hunt, K.J., Resendez, R.G., Williams, K., Haffner, S.M. and Stern, M.P. (2004) National Education Program versus World Health Organization metabolic syndrome in relation to all-cause and cardiovascular mortality in the San Antonio Heart Study. Circulation, 110, 1251-1257. doi:10.1161/01.CIR.0000140762.04598.F9

[17] Girman, C.J., Rhodes, T., Mercuri, M., Pyorala, K., Kjekshus, J., Pedersen, T.R., Beere, P.A., Gotto, A.M. and Clearfield, M. (2004) The metabolic syndrome and risk of major coronary events in the Scandinavian Simvastatin Survival Study (45) and the Air Force/Texas Coronary Atherosclerosis Prevention Study (AFCAPS/Tex/CAPS). American Journal of Cardiology, 93, 136-141. doi:10.1016/j.amjcard.2003.09.028

[18] Al-Isa, A.N., Akanji, A.O. and Thalib, L. (2010) Prevalence of metabolic syndrome among female Kuwaiti adolescents, using two criteria. British Journal of Nutrition, 
103, 77-81. doi:10.1017/S0007114509991425

[19] Calcaterra, V., Klersy, C., Muratori, T., Telli, S., Caramagna, C., Scaglia, F., Cisternino, M. and Larizza, D. (2007) Prevalence of metabolic syndrome (MS) in children and adolescents with varying degrees of obesity. Clinical Endocrinology, 86, 868-872.

[20] Ryu, S.Y., Kweon, S.S., Park, H.C., Shin, J.H. and Rhee, J.A. (2007) Obesity and the metabolic syndrome in Korean adolescents. Journal of Korean Medical Science, 22, 513-517. doi:10.3346/jkms.2007.22.3.513

[21] Xu, T.Q. and Ji, C.Y. (2008) Prevalence of the metabolic syndrome in secondary school adolescents in Beijing, China. Acta Paediatrica, 97, 348-353. doi:10.1111/j.1651-2227.2008.00665.x

[22] Pan, Y. and Pratt, C.A. (2008) Metabolic syndrome and its association with diet and physical activity in US ado- lescents. Journal of the American Dietetic Association, 108, 276-286. doi:10.1016/j.jada.2007.10.049

[23] Lim, S., Jang, H.C., Park, K.S., Lee, H.K., Chung, H.R., Joung, H.J. and Cho, S.I. (2008) Changes in metabolic syndrome of Korean children and adolescents in the period 1998 to 2001. Journal of Endocrinological Investigation, 31, 327-333.

[24] Al-Shayji, I.A. and Akanji, A.O. (2004) Obesity indices and major components of metabolic syndrome in young adult Arab subjects. Annals of Nutrition and Metabolism, 48, 1-7. doi:10.1159/000075079

[25] Mansour, A.A., Al-Hassan, A.A. and Al-Jazairi, M.I. (2007) Cut-off values for waist circumference in rural Iraqi adults for the diagnosis of metabolic syndrome. $\mathrm{Ru}$ ral Remote Health, 7, 765. 